\title{
A review of literature on diabetes self-management: Scope for research and practice in India
}

\author{
Subha Gomathy Sridharan, Mahati Chittem, Nagesh Muppavaram \\ Department of Liberal Arts, Indian Institute of Technology Hyderabad, Sangareddy, Telangana, India
}

\section{A B S T R A C T}

Diabetes self-management is a complex phenomenon which refers to patients' attending checkups regularly and adhering to a physician-prescribed regimen including following a strict diet, exercise, self-monitoring of blood glucose (SMBG), and medication. This review will unpack the facilitators and barriers for each of the recommended lifestyle change for improving diabetes management (i.e. the behaviors of diet, exercise, SMBG, and medication). Referred to as the "diabetes capital" of the world, the review will focus on diabetes self-management research and interventions in India, highlighting the dearth for appropriate evidence-based programs in the country. Finally, the review will discuss the scope for future research and practice within this field in the Indian context.

Key words: Adherence, diabetes, India, psychosocial, self-management

\section{INTRODUCTION}

Self-management is a concept emerging from Albert Bandura's social cognitive theory which is based on the principles of self-regulation, self-control, and self-efficacy. ${ }^{[1,2]}$ Self-regulation refers to an individual's ability to monitor or manage oneself..$^{[3]}$ Self-regulation constitutes three components: (i) Self-observation: Monitoring ones' behavior, (ii) self-evaluation: Making judgments about ones' behavior in comparison with their own standards and their environmental conditions, and (iii) self-reaction: The emotional responses associated with the behavior. ${ }^{[4]}$ Self-control is the process of acquiring skills to gain personal control over one's thoughts and actions to achieve the target behavior. ${ }^{[5,6]}$ Finally, self-efficacy refers to the extent to which an individual is capable of performing a particular task or behavior. Self-efficacy

\begin{tabular}{|l|l|}
\hline \multicolumn{2}{|c|}{ Access this article online } \\
\hline Quick Response Code: & Website: \\
\hline & www.joshd.net \\
\hline & \\
\hline & \\
\hline
\end{tabular}

takes into account individuals' attitudes, perceptions, and emotions in relation to the behavior. ${ }^{[7]}$

Within the domain of diabetes, self-management involves (i) attending regular checkups, and (ii) adherence to a physician-prescribed, tailored medication, and lifestyle. ${ }^{[8-12]}$ Owing to the major and everyday lifestyle modifications posed by diabetes, compliance to physician recommendations is frequently examined in psychosocial diabetes research. In this regard, it is observed that patients with diabetes who follow the recommended diet, exercise, medication, and regular monitoring of glucose report better glycemic control than their nonadherent counterparts (i.e., patients with poor glycemic control)..$^{[9,13,14]}$ Effective diabetes self-management also improves other physiological

\footnotetext{
This is an open access article distributed under the terms of the Creative Commons Attribution-NonCommercial-ShareAlike 3.0 License, which allows others to remix, tweak, and build upon the work non-commercially, as long as the author is credited and the new creations are licensed under the identical terms.
}

For reprints contact: reprints@medknow.com

How to cite this article: Sridharan SG, Chittem M, Muppavaram N. A review of literature on diabetes self-management: Scope for research and practice in India. J Soc Health Diabetes 2016;4:108-14.

Corresponding Author: Dr. Mahati Chittem, Department of Liberal Arts, Indian Institute of Technology Hyderabad, Kandi, Sangareddy - 502285 , Telangana, India. E-mail: mahati@iith.ac.in 
parameters such as body weight, blood pressure, and the lipid profile ${ }^{[15]}$ and has positive outcomes on a wide range of psychosocial and economic aspects for the patient such as a decrease in levels of distress, anxiety and depression, ${ }^{[16]}$ optimal utilization of health-care services, ${ }^{[17]}$ and reduction of diabetes-related costs. ${ }^{[18-20]}$

The current review will elaborate on the key patients' behaviors linked to self-management, i.e., diet, exercise, self-monitoring, and medical adherence. Following this, the article will examine the current status of diabetes self-management research and interventions in India and conclude with reflecting on the scope for research and practice within this area in India.

\section{Methods of ARTICLE EXtraction AND SYNTHESIS}

To ensure a comprehensive review of research in diabetes self-management, the authors embarked upon a rigorous and step-by-step article extraction and synthesis process. The first author systematically located articles in a variety of databases including Science Direct, PubMed, Web of Science, and Google Scholar. Key terms included "self-management," "chronic illness," "diabetes," "adherence," "diabetes self-management," "diabetes regimen," "India and diabetes," "diet and diabetes," "exercise and diabetes," "self-monitoring and diabetes," and "medication and diabetes." These terms were used individually and together to ensure an extensive literature search. Relevant articles were selected and collated based on the broader objective of the review, i.e. examining facilitators and barriers for diabetes self-management. The first and second authors then read, discussed, and summarized each article. From this common trends and findings were identified and synthesized to form the final review.

\section{Diet management}

During diabetes consultations, physicians examine patients' dietary habits and accordingly suggest alterations to ensure glycemic control. ${ }^{[21]}$ Research identified several key factors associated with improved dietary adherence which will be discussed in turn. First, it was found that dietary knowledge plays a vital role in long-term nutritional self-care. ${ }^{[22-24]}$ Research indicates that it is especially beneficial for patients to receive information about the different types of diets as it increases their awareness. ${ }^{[9,13]}$ Second, patient factors such as self-regulation, self-control, and self-discipline were found to influence dietary adherence. This may be because patients who exhibit high levels of self-regulation are more likely to plan ahead and execute specific behaviors. ${ }^{[25]}$ Further, patients who have high levels of self-control and self-discipline are more likely to change their diet and maintain a healthier diet than their counterparts. ${ }^{[13,26,27]}$ Third, it was found that social support plays a significant role in adherence to the prescribed diet. ${ }^{[9,13,28-30]}$ Interestingly, research highlights that patients are able to identify specific individuals to fulfill a particular supportive care need. For example, to help maintain dietary adherence, patients preferred to receive informational support from their physician, and emotional and logistical support from their family members. ${ }^{[31]}$ Finally, patients' illness perceptions, which is their beliefs/interpretations about their illness, were found to predict dietary adherence. ${ }^{[27]}$ Beliefs about treatment effectiveness, severity of the illness, perceived personal control over the illness, and beliefs about the consequences shape the patients' dietary behaviors. ${ }^{[32,33]}$

On the other hand, prohibitive costs of maintaining a changed diet prevent patients from complying with dietary recommendations. ${ }^{[25,34]}$ A major modification prescribed by physicians is to shift from a simple carbohydrate to a complex carbohydrate diet. ${ }^{[35]}$ However, in South India, for instance, this can be impractical as patients will have to replace their easily available and cheap sources of simple carbohydrates (e.g., polished white rice) with considerably more expensive and difficult to procure complex carbohydrates. ${ }^{[36]}$ Indeed, the second key barrier for dietary adherence is doctor-patient relationship. Research indicates that when physicians prescribe a diet that is not sensitive to patients' socioeconomic and cultural background, it leads to poor dietary compliance among patients. ${ }^{[37]}$ Finally, patients' psychological well-being is linked to dietary adherence, such that patients reporting high levels of psychological distress such as stress, depression, anxiety, and anger associated with following a prescribed diet are more likely to discontinue the changes to their diet..$^{[9,13]}$

\section{Exercise management}

A major predictor of glycemic control is the amount, type, and frequency of exercise that patients engage in. ${ }^{[9,11-13,37]}$ In line with the primary facilitating factor in dietary adherence, knowledge was associated with exercise and effective diabetes management. Awareness especially about the different types of exercise and having an opportunity to select a specific exercise promotes adherence. ${ }^{[16]}$ Second, social support played a crucial role in adherence, particularly in terms of engaging in exercise. ${ }^{[9]}$ Research on exercise adherence shows that patients with diabetes benefit from both their family and friends actively engaging in the physical activity with 
them. ${ }^{[13]}$ Finally, the type of exercise routine and duration of the exercise are associated with compliance, such that an exercise routine which has elements of fun and aims to achieve short-term goals motivates patients which, in turn, promotes self-management. ${ }^{[38]}$

In contrast, logistical issues (e.g., access to exercise, time, and weather) are closely linked with patients' exercise noncompliance. ${ }^{[39]}$ Of note, time constraints and difficulty with allocating time regularly for physical activity are considered to be key obstacles for exercise adherence. ${ }^{[26]}$ Second, having a comorbid condition obstructs exercise adherence, ${ }^{[40]}$ thus highlighting the need to take into account disease burden and associated complexities. Third, sociocultural norms about exercise influence patients' participation in physical activity, with patients reporting negative attitudes toward exercise and/or social stigma being main reasons for the lack of exercise adherence. ${ }^{[30]}$ Finally, research indicates that having an external locus of control (i.e., the belief that one's life is controlled by environmental factors, chance or fate) toward diabetes management is inversely linked with patients' ability to follow an exercise routine. That is, patients who perceive a lack of control over their illness are more likely to fail in planning and executing their daily exercise routine than their counterparts. ${ }^{[41]}$

\section{Self-monitoring and medical adherence}

Self-monitoring of blood glucose (SMBG) refers to the practice of patients regularly checking their glycemic index to manage their diabetes promptly. ${ }^{[9]}$ Self-monitoring is closely associated with patients' medical literacy, especially in terms of their levels of diabetes-related knowledge and ability to understand or interpret medical readings. ${ }^{[42]}$ Second, self-discipline, wherein patients who regularly monitor their blood glucose levels, is associated with better self-management. ${ }^{[13]}$ Further, research indicates that patients who receive adequate support from their significant others are able to overcome the challenges of SMBG (e.g., interpretation of medical readings, dealing with psychological distress, and so on). ${ }^{[43,44]}$

Conversely, physical discomfort is revealed to be a deterrent to engage in SMBG, with patients reporting that the pain from a pinprick to the finger is a major reason for avoiding monitoring their blood glucose levels. ${ }^{[26]}$ Second, physicians' levels of interest in patients' SMBG efforts and communication skills with the patient pose as a barrier to self-management. To elaborate, physicians' lack of interest toward or insufficient acknowledgment of patients' SMBG efforts and/or medical readings is negatively associated with adherence of self-monitoring. ${ }^{[29]}$ Further, physicians' lack of communication with their patient (e.g., not discussing the medical readings) is related to decreased levels of motivation to self-monitor among patients. ${ }^{[45]}$

Owing to the fundamental role that medication plays in a diabetes diagnosis, medical adherence is considered to be a vital behavioral factor in determining effective diabetes management. ${ }^{[9,11-13]}$ The two major facilitating factors in this area are patients' relationship with their treating physician and their self-discipline. ${ }^{[4]}$ First, physicians who spend adequate time with their patients and provide a follow-up service aid in medical adherence. ${ }^{[26,46]}$ Emphasizing the central role of physician communication within the patient-physician relationship, research indicates that when physicians take the time to explain the need for medication and clarify doubts regarding the side effects of the medication, it improves patients' medical literacy which, in turn, promotes their ability to manage their medication appropriately. ${ }^{[47]}$ Consistent with the research on SMBG behaviors, patients reporting high levels of self-discipline are more likely to make the process of taking medication systematic and a routine, thereby adding a structured, well-thought approach to their diabetes management. ${ }^{[13]}$ Interestingly, this review was able to identify diabetes-related social stigma as the only salient barrier for optimal medication management. It is suggested that patients who experience negative social perceptions toward diabetes are hindered in their ability to comply with the medical recommendations, ${ }^{[11]}$ thus highlighting the influential role of social network/community perceptions and support in patients' self-management.

\section{Diabetes Self-MANAgement ReSEARCH AND INTERVENTIONS IN INDIA}

Surprisingly, in spite of the staggering prevalence of diabetes, ${ }^{[48]}$ there is limited research emerging from India examining self-management in diabetes. Key research in India includes Nachman et al.'s study examining the effectiveness of a mobile-based self-management system, named Jog Falls, among Indian diabetes patients. ${ }^{[49]}$ This wearable sensor tracked the individual's physical activity and diet and provided this information to both the patient and the physician. The Jog Falls system aided in a significant weight reduction among participants and in improving patients' self-awareness of their caloric intake. While this study sheds light on the usefulness of a technological intervention to promote dietary and exercise adherence, it does not explore the experiential aspects of the illness (e.g., decision-making processes, doctor-patient relationship) and the economic feasibility of using the device. Further, the study did not include a diabetes education element to equip patients with information 
about the roles of diet and exercise in disease management. Selvaraj et al. explored self-care practices among diabetes patients in terms of their diet, physical activity, foot care, adherence to medications, and blood glucose monitoring. ${ }^{[50]}$ Among these behaviors, avoidance of selected food items (99.4\%), taking medication as per the recommendation (95.6\%), checking one's blood sugar at least once in 3 months $(78 \%)$ were the most frequently adhered to. Although this study highlights patients' compliance with and/or engagement in the recommended self-care practices, it did not take into account their levels of medical literacy, the doctor-patient relationship, and social support in self-management.

Addressing the need for capacity-building in semi-urban and rural regions of India, Murugesan et al. developed a 5-day training program on diabetes care for primary care physicians from six states in India (Tamil Nadu, Kerala, erstwhile Andhra Pradesh, Karnataka, Orissa, and Gujarat). Targeting groups of 40-60 physicians each, the program covered a wide range of topics including: (1) Diagnosis, treatment (drug and nutrition therapy), and complications relating to diabetes, (2) lifestyle modification and stress management, (3) diabetes prevention and foot care, (4) diabetes advocacy in the community and enhancing physician-patient communication skills, (5) promoting professional networking and team building to improve diabetes care/management at the primary care setting. ${ }^{[51]}$ The training modules were delivered through face-to-face lectures and interactive group discussions. The program was positively received and significantly improved physicians' knowledge about diabetes-related topics (e.g., diagnosis, treatment, and complications). Interestingly, the physicians suggested a need for providing similar educational material to patients. Indeed, emphasizing the need for patient education, Raheja et al. reported that nearly half the patients in India had poor glycemic control with most patients being unaware of diet therapy in the management of their illness. ${ }^{[52]}$ Correspondingly, Kalra et al. highlighted the pressing need to include both patient and physician perspectives on diabetes management so that not only are the medical factors of the disease taken into account but also the psychosocial aspects of its management. ${ }^{[53]}$

\section{OVERARCHING CONCLUSIONS ON THE FACTORS DETERMINING DIABETES SELF-MANAGEMENT: SCOPE AND SUGGESTIONS FOR FUTURE RESEARCH AND PRACTICE IN INDIA}

This review revealed that self-management is a complex concept which needs to incorporate the roles of several stakeholders including the patient, physician, family, friends, the wider community, policymakers, and the public health system. The overarching factors that contribute to patients' adherence are medical literacy, illness beliefs and attitudes, the doctor-patient relationship, and patient characteristics. This section of the review will discuss each of these factors in relation to the Indian context of diabetes care and explore the scope for future research and practice in India and relevant suggestions [Table 1]. It is important to note that although these factors will be discussed independently, they are not mutually exclusive and are, in fact, interwoven such that one may impact the other in an intricate and complicated manner.

A major resource for improving medical literacy in this review was observed to be the physician, indicating that patients continue to depend on the physician for reliable, valid, and convincing informational support. This may be challenging to the physician as well as problematic for the patient as there is only so much time and information that their treating physician can communicate to individual patients. Consequently, this dependence on the physician compromises the level and quality of medical knowledge available to patients which, in the end, is a barrier toward effective self-management. ${ }^{[26,45-47]}$ Given the enormous disease burden and skewed physician to patient ratio of $1: 1800$ in India, ${ }^{[54]}$ expecting the physician to be the sole provider of medical informational support may be onerous and unrealistic. To improve medical literacy about diabetes among Indian patients, it may be necessary to alter patients' perceptions of who (and, indeed, what) is a reliable source of health/medical information and direct them toward alternate, authenticated channels of information (e.g., establishing professionally guided peer-to-peer learning groups).

This review found that patients' and their social network's (e.g., family, friends, and community) illness beliefs and attitudes are a crucial factor in determining successful diabetes self-management. When these beliefs are positive, they create a supportive environment to initiate and/or maintain adherence. However, when patients and their social network have negative beliefs, then it impedes the patient's ability to engage in adherence activities. ${ }^{[29]}$ Not surprisingly, research indicates that illness perceptions are closely linked with medical literacy. ${ }^{[41,55]}$ Hence, an added benefit of improving patient education will be to engender and maintain positive personal and social views toward diabetes. Extending this, it may be useful to educate communities on diabetes with a focus on changing or eliminating negative perceptions toward diabetes thus increasing community level support for 


\begin{tabular}{|c|c|c|}
\hline Need & Scope & Suggestion \\
\hline $\begin{array}{l}\text { Improving patients' medical } \\
\text { literacy }\end{array}$ & $\begin{array}{l}\text { Alter patients' perceptions of reliable } \\
\text { sources of health/medical information }\end{array}$ & $\begin{array}{l}\text { Direct patients towards alternate, authenticated channels } \\
\text { of information (e.g., establishing professionally guided } \\
\text { peer-to-peer learning groups) }\end{array}$ \\
\hline $\begin{array}{l}\text { Correct negative illness beliefs } \\
\text { at an individual and community } \\
\text { level }\end{array}$ & $\begin{array}{l}\text { Teach communities on diabetes with } \\
\text { a focus on changing or eliminating } \\
\text { negative perceptions towards diabetes }\end{array}$ & $\begin{array}{l}\text { Education and awareness camps/seminars/workshops } \\
\text { within communities which illustrate the short- and } \\
\text { long-term benefits of diabetes adherence for patients and } \\
\text { their families. }\end{array}$ \\
\hline $\begin{array}{l}\text { Optimal doctor-patient } \\
\text { relationship }\end{array}$ & $\begin{array}{l}\text { Incorporate communication skills } \\
\text { training (CST) for physicians and } \\
\text { patients }\end{array}$ & $\begin{array}{l}\text { Train physicians on how to tailor information for individual } \\
\text { patients, correcting inaccurate diabetes-related beliefs, } \\
\text { and providing information about the link between } \\
\text { the recommended behaviour and effective disease } \\
\text { management. } \\
\text { Training patients in question-asking and being proactive in } \\
\text { the medical encounter }\end{array}$ \\
\hline $\begin{array}{l}\text { Early identification of patients } \\
\text { who require additional support }\end{array}$ & $\begin{array}{l}\text { Conduct psychological research to } \\
\text { better understand the connection } \\
\text { between patients' personality } \\
\text { and their corresponding diabetes } \\
\text { self-management efforts }\end{array}$ & $\begin{array}{l}\text { Mixed methods approach (i.e., qualitative and quantitative } \\
\text { techniques) focusing on patients' experiences and } \\
\text { accounts of compliance. } \\
\text { Findings can be used to develop protocols for early } \\
\text { identification and provision of appropriate support }\end{array}$ \\
\hline
\end{tabular}

patients with the illness. This may be achieved through a variety of methods such as education and awareness camps/seminars/workshops within communities which illustrate the short- and long-term benefits of diabetes adherence for patients and their families. These programs can also encourage collective brainstorming of ideas to create a supportive physical and social environment for patient well-being.

Taking into account, the importance of the doctor-patient relationship as both a facilitator and barrier to adherence, it may be vital to incorporate communication skills training (CST) for physicians and patients so as to enable effective informational exchange. Research examining CST for oncologists reported positive findings such as increasing physicians' confidence in communicating with patients and improved patient outcomes. ${ }^{[56,57]}$ It may be useful to test similar CST programs for physicians that could include modules on how to tailor information for individual patients, correcting inaccurate diabetes-related beliefs, and providing information about the link between the recommended behavior and effective disease management. Patients may need training in skills such as question-asking and being proactive in the medical encounter. Skills-building techniques such as the question prompts ${ }^{[58]}$ can be introduced to patients with the aim of improving their ability to discuss health issues most important to them.

However, these training programs need to take into account individual patient characteristics. In this review, it was observed that patients' levels of self-regulation, self-control, and self-discipline facilitated self-management, suggesting a need to introduce and support these behaviors as soon as one is diagnosed with diabetes. Further, worldwide research established that maintaining these behaviors helps patients tailor their self-management techniques, instills a sense of ownership toward the illness, and manages their negative responses to the illness, thus indicating the need to better understand the connection between patients' personality and their corresponding diabetes self-management efforts. ${ }^{[26,59]}$ This can be achieved by applying a mixed methods approach (i.e., qualitative and quantitative techniques) in psychology research focusing on patients' experiences and accounts of compliance, thereby shedding light on the experiential aspects of diabetes self-management. Moreover, this research can help identify and/or inform the development of protocols for early identification of patients who require additional support in terms of their self-regulation, self-control, and self-discipline.

Thus, through the help of this review, it can be understood that there is vast scope for research and medical practice in India to improve patient care. This can be achieved by considering the several nuances involved in diabetes self-management in India such as the sociocultural contexts of health literacy, illness beliefs, the role of social support, diabetes-related knowledge, and the doctor-patient relationship.

\section{Financial support and sponsorship}

This review was funded through the Doctoral Fellowship from the Ministry of Human Resources and Development, Government of India, India, provided to the first author (SG).

\section{Conflicts of interest}

There are no conflicts of interest. 


\section{REFERENCES}

1. Bandura A. Social Foundations of Thought and Action: A Social Cognitive Theory. NJ, USA: Prentice Hall, Inc.; 1986.

2. Rosal MC, Ockene IS, Restrepo A, White MJ, Borg A, Olendzki B, et al. Randomized trial of a literacy-sensitive, culturally tailored diabetes self-management intervention for low-income latinos: Latinos en control. Diabetes Care 2011;34:838-44.

3. Halberstadt J, Makkes S, de Vet E, Jansen A, Nederkoorn C, van der Baan-Slootweg $\mathrm{OH}$, et al. The role of self-regulating abilities in long-term weight loss in severely obese children and adolescents undergoing intensive combined lifestyle interventions (HELIOS); rationale, design and methods. BMC Pediatr 2013;13:41.

4. Rymal AM, Martini R, Ste-Mari DM. Self-regulatory processes employed during self-modeling: A qualitative analysis. Sports Psychol 2010;24:1-15.

5. Bonsaksen T, Lerdal A, Fagermoen MS. Trajectories of illness perceptions in persons with chronic illness: An explorative longitudinal study. J Health Psychol 2015;20:942-53.

6. Lawton J, Ahmad N, Peel E, Hallowell N. Contextualising accounts of illness: Notions of responsibility and blame in white and South Asian respondents' accounts of diabetes causation. Sociol Health IIIn 2007;29:891-906.

7. Bandura A. Social cognitive theory of self-regulation. Organizational Behavior and Human Decision Processes 1991;50:248-87.

8. Morowatisharifabad MA, Mahmoodabad SS, Baghianimoghadam $\mathrm{MH}$, Tonekaboni NR. Relationships between locus of control and adherence to diabetes regimen in a sample of Iranians. Int J Diabetes Dev Ctries 2010;30:27-32.

9. de Alba Garcia JG, Rocha AL, Lopez I, Baer RD, Dressler W, Weller SC. "Diabetes is my companion": Lifestyle and self-management among good and poor control Mexican diabetic patients. Soc Sci Med 2007;64:2223-35.

10. Adriaanse MC, Bosmans JE. Short reports diabetes prevalence, diabetes regimen and co-morbidity in depressed patients compared with non-depressed patients in primary care in the Netherland. Diabet Med 2010;27:718-22.

11. Greenhalgh T, Collard A, Campbell-Richards D, Vijayaraghavan S, Malik F, Morris J, et al. Storylines of self-management: Narratives of people with diabetes from a multiethnic inner city population. J Health Serv Res Policy 2011;16:37-43.

12. Ralston JD, Revere D, Robins LS, Goldberg HI. Patients' experience with a diabetes support programme based on an interactive electronic medical record: Qualitative study. BMJ 2004;328:1159.

13. Brewer-Lowry AN, Arcury TA, Bell RA, Quandt SA. Differentiating approaches to diabetes self-management of multi-ethnic rural older adults at the extremes of glycemic control. Gerontologist 2010;50:657-67.

14. Garc65-Prc657-67.erontologisDilla T, Gil-Guillil V, Orozco-Beltrro D. Adherence to therapies in patients with type 2 diabetes. Diabetes Ther 2013;4:175-94.

15. Colberg SR, Rubin RR, Sigal RJ, Chasan-Taber L, Fernhal B, Albright AL, et al. Exercise and type 2 diabetes. Diabetes Care 2010;33:47-67.

16. Skinner TC, Carey ME, Cradock S, Daly H, Davies MJ, Doherty Y, et al. Diabetes education and self-management for ongoing and newly diagnosed (DESMOND): Process modelling of pilot study. Patient Educ Couns 2006;64:369-77.

17. Panagioti M, Richardson G, Small N, Murray E, Rogers A, Kennedy $A$, et al. Self-management support interventions to reduce health care utilisation without compromising outcomes:
A systematic review and meta-analysis. BMC Health Serv Res 2014;14:356.

18. Buszewicz M, Rait G, Griffin M, Nazareth I, Patel A, Atkinson A, et al. Self management of arthritis in primary care: Randomised controlled trial. BMJ 2006;333:879.

19. Lorig KR, Ritter P, Stewart AL, Sobel DS, Brown BW Jr., Bandura $A$, et al. Chronic disease self-management program: 2-year health status and health care utilization outcomes. Med Care 2001;39:1217-23.

20. Moattari M, Ghobadi A, Beigi P, Pishdad G. Impact of self management on metabolic control indicators of diabetes patients. J Diabetes Metab Disord 2012;11:6.

21. Maggio CA, Pi-Sunyer FX. The prevention and treatment of obesity. Application to type 2 diabetes. Diabetes Care 1997;20:1744-66.

22. Siddiqui A, Gul A, Ahmedani MY, Masood Q, Miyan Z. Compliance to diet counselling provided to patients with type 2 diabetes at a tertiary care hospital. J Diabetol 2010;1:1-6.

23. Chandalia M, Garg A, Lutjohann D, von Bergmann K, Grundy SM, Brinkley LJ. Beneficial effects of high dietary fiber intake in patients with type 2 diabetes mellitus. N Engl J Med 2000;342:1392-8.

24. Al-Sinani M, Min Y, Ghebremeskel K, Qazaq HS. Effectiveness of and adherence to dietary and lifestyle counselling: Effect on metabolic control in type 2 diabetic Omani patients. Sultan Qaboos Univ Med J 2010;10:341-9.

25. Fisher EB, Brownson CA, O'Toole ML, Shetty G, Anwuri VV, Glasgow RE. Ecological approaches to self-management: The case of diabetes. Am J Public Health 2005;95:1523-35.

26. Chlebowy DO, Hood S, LaJoie AS. Facilitators and barriers to self-management of type 2 diabetes among urban African American adults: Focus group findings. Diabetes Educ 2010;36:897-905.

27. Otovwe A, Emmanuel O. Patterns of adherence to management among patients with type 2 diabetes mellitus in South-South Region of Nigeria. J Soc Health Diabetes 2015;3:115.

28. Gerstle JF, Varenne H, Contento I. Post-diagnosis family adaptation influences glycemic control in women with type 2 diabetes mellitus. J Am Diet Assoc 2001;101:918-22.

29. Gallant MP. The influence of social support on chronic illness self-management: A review and directions for research. Health Educ Behav 2003;30:170-95.

30. Greaves CJ, Sheppard KE, Abraham C, Hardeman W, Roden M, Evans $\mathrm{PH}$, et al. Systematic review of reviews of intervention components associated with increased effectiveness in dietary and physical activity interventions. BMC Public Health 2011;11:119.

31. Vijan S, Hayward RA, Ronis DL, Hofer TP. Brief report: The burden of diabetes therapy: Implications for the design of effective patient-centered treatment regimens. J Gen Intern Med 2005;20:479-82.

32. Broadbent E, Donkin L, Stroh JC. Illness and treatment perceptions are associated with adherence to medication, diet and exercise in diabetic patients. Diabet Med 2009;26:5-13.

33. Washington G, Wang-Letzkus MF. Self-care practices, health beliefs, and attitudes of older diabetic Chinese Americans. J Health Hum Serv Adm 2009;32:305-23.

34. Uchenna O, ljeoma E, Pauline E, Sylvester O. Contributory factors to diabetes dietary regimen non adherence in adults with diabetes. World Acad Sci Eng Technol 2010;4:644-51.

35. Fukagawa NK, Anderson JW, Hageman G, Young VR, Minaker KL. High-carbohydrate, high-fiber diets increase peripheral insulin sensitivity in healthy young and old adults. Am J Clin Nutr 1990;52:524-8.

36. Sudha V, Spiegelman D, Hong B, Malik V, Jones C, Wedick NM, 
et al. Consumer acceptance and preference study (CAPS) on brown and undermilled Indian rice varieties in Chennai, India. J Am Coll Nutr 2013;32:50-7.

37. Brown SA, Garcia AA, Kouzekanani K, Hanis CL. Culturally competent diabetes self-management education for Mexican Americans: The Starr County border health initiative. Diabetes Care 2002;25:259-68.

38. Johnson MR. Perceptions of barriers to healthy physical activity among Asian communities. Sport Educ Soc 2000;5:51-70.

39. Thomas N, Alder E, Leese GP. Barriers to physical activity in patients with diabetes. Postgrad Med J 2004;80:287-91.

40. Balhara YP, Sagar R. Correlates of anxiety and depression among patients with type 2 diabetes mellitus. Indian J Endocrinol Metab 2011;15 Suppl 1:S50-4.

41. Greenhalgh T, Helman C, Chowdhury AM. Health beliefs and folk models of diabetes in British Bangladeshis: A qualitative study. BMJ 1998;316:978-83.

42. Onwudiwe NC, Mullins CD, Winston RA, Shaya FT, Pradel FG, Laird A, et al. Barriers to self-management of diabetes: A qualitative study among low-income minority diabetics. Ethn Dis 2011;21:27-32.

43. Bergenstal RM, Gavin JR $3^{\text {rd }}$; Global Consensus Conference on Glucose Monitoring Panel. The role of self-monitoring of blood glucose in the care of people with diabetes: Report of a global consensus conference. Am J Med 2005;118 Suppl 9A: 1S-6S.

44. Costa V, Pereira R, Pedras S. Partner support, social-cognitive variables and their role in adherence to self-monitoring of blood glucose in type 2 diabetes. Europ Diabetes Nurs 2012;9:81-7.

45. Matthews SM, Peden AR, Rowles GD. Patient-provider communication: Understanding diabetes management among adult females. Patient Educ Couns 2009;76:31-7.

46. Borgsteede SD, Westerman MJ, Kok IL, Meeuse JC, de Vries TP, Hugtenburg JG. Factors related to high and low levels of drug adherence according to patients with type 2 diabetes. Int $\mathrm{J}$ Clin Pharm 2011;33:779-87.

47. Norris SL, Lau J, Smith SJ, Schmid CH, Engelgau MM. Self-management education for adults with type 2 diabetes: A meta-analysis of the effect on glycemic control. Diabetes Care 2002;25:1159-71.

48. Vermeire E, Royen PV, Coenen S, Wens J, Denekens J. The adherence of type 2 diabetes patients to their therapeutic regimens: A qualitative study from the patient's perspective. Pract Diabetes Int 2003;20:209-14.

49. Nachman L, Baxi A, Bhattacharya S, Darera V, Deshpande P, Kodalapura N, et al. Jog Falls: A pervasive healthcare platform for diabetes management. Lect Notes Comput Sci 2010;6030:94-111.

50. Selvaraj K, Ramaswamy G, Radhakrishnan S, Thekkur P, Chinnakali P, Roy G. Self-care practices among diabetes patients registered in a chronic disease clinic in Puducherry, South India. J Soc Health Diabetes 2016;4:25.

51. Murugesan N, Shobana R, Snehalatha C, Kapur A, Ramachandran A. Immediate impact of a diabetes training programme for primary care physicians - An endeavour for national capacity building for diabetes management in India. Diabetes Res Clin Pract 2009;83:140-4.

52. Raheja BS, Sadikot SM, Phatak RB, Rao MB. Significance of the $\mathrm{N}-6 / \mathrm{N}-3$ ratio for insulin action in diabetes. Ann N Y Acad Sci 1993;683:258-71.

53. Kalra B, Sridhar GR, Madhu K, Balhara YP, Sahay RK, Kalra S. Psychosocial management of diabetes in pregnancy. Indian $\mathrm{J}$ Endocrinol Metab 2013;17:815-8.

54. Deo MG. "Doctor population ratio for India ahay RK, Kalra S. Psychosocial management of dia

55. Sarkar U, Karter AJ, Liu JY, Moffet HH, Adler NE, Schillinger D. Hypoglycemia is more common among type 2 diabetes patients with limited health literacy: The diabetes study of Northern California (DISTANCE). J Gen Intern Med 2010;25:962-8.

56. Bylund $\mathrm{CL}$, Brown $\mathrm{R}$, Gueguen JA, Diamond $\mathrm{C}$, Bianculli J, Kissane DW. The implementation and assessment of a comprehensive communication skills training curriculum for oncologists. Psychooncology 2010;19:583-93.

57. Stiefel F, Favre N, Despland JN. Communication skills training in oncology: It works! Recent Results Cancer Res 2006;168:113-9.

58. Butow PN, Dunn SM, Tattersall MH, Jones QJ. Patient participation in the cancer consultation: Evaluation of a question prompt sheet. Ann Oncol 1994;5:199-204.

59. King DK, Glasgow RE, Toobert DJ, Strycker LA, Estabrooks PA, Osuna D, et al. Self-efficacy, problem solving, and social-environmental support are associated with diabetes self-management behaviors. Diabetes Care 2010;33:751-3. 